\title{
Alterations in Cerebral Blood Flow and Oxygen Consumption during Prolonged Hypocarbia
}

\author{
NANCY B. HANSEN, PHILIP T. NOWICKI, RANDY R. MILLER, THOMAS MALONE, \\ REX G. BICKERS, AND JAMES A. MENKE \\ Department of Pediatrics, Ohio State University, Columbus Children's Hospital, Columbus, Ohio 43205
}

\begin{abstract}
The effect of prolonged ( $2 \mathrm{~h}$ ) hypocarbia on cerebral blood flow, oxygen delivery, extraction, and consumption was studied in eight, 1 - to 4-day-old piglets. Hyperventilation to $\mathrm{PaCO}_{2}<20 \mathrm{~mm} \mathrm{Hg}$ acutely $(30 \mathrm{~min})$ decreased cerebral blood flow and oxygen oconsumption. Cerebral oxygen consumption was subsequently restored via increases in cerebral blood flow and thus, cerebral oxygen delivery. Cerebral oxygen extraction rose from a normocarbic baseline of 50 to $75 \%$ with acute hypocarbia and was maintained at this level. The percent decrease in blood flow to the cerebrum was greater than that to other brain regions during hypocarbia. (Pediatr Res 20: 147150, 1986)
\end{abstract}

Hyperventilation-induced respiratory alkalosis is a principal form of therapy used in newborn infants with persistent pulmonary hypertension. A potential complication of this therapeutic modality is brain ischemia, caused by hypocarbia-induced vasoconstriction of the cranial arteries. In several newborn animal species, acute respiratory alkalosis reduced brain blood flow to $50 \%$ of normocarbic levels indicating that significant brain oxygen deprivation might occur during hypocarbic alkalosis $(1,2)$. However, follow-up studies of infants managed with prolonged hypocarbic alkalosis have demonstrated a paucity of significant neurologic sequelae, despite the anticipated impact of hyperventilation on the cerebral circulation $(3,4)$. The apparent discrepancy between human and animal studies might be explained by variations in the response of the cerebral vasculature to extreme hypocarbia over time (5). Thus, we hypothesized that there may be an "escape" from the acute vasoconstrictive effects of hypocarbia, such that brain blood flow returns toward baseline despite the persistance of hypocarbic alkalosis. The purpose of this study was to characterize brain blood flow, oxygen delivery, and utilization over time during constant severe hypocarbia in the newborn piglet.

\section{MATERIALS AND METHODS}

Animal preparation. Twelve, 1- to 4-day-old farm bred piglets were obtained on the morning of the study. The weight of the piglets was $1.7 \pm 0.5 \mathrm{~kg}$. All surgical procedures were performed under nitrous oxide inhalation (70\%) with local infiltration of the surgical incisions with $1 \%$ lidocaine. Catheters were positioned in the left ventricle (via femoral artery), ascending aorta (via axillary artery), and lower abdominal zorta (via femoral artery). A tracheotomy was performed and muscle paralysis

Received May 28, 1985: accepted September 20, 1985.

Reprint address Nancy B. Hansen, M.D., Department of Pediatrics, Ohio State University. Columbus Children's Hospital, 700 Children's Drive, Columbus, $\mathrm{OH}$ 43205.

Supported by Children's Hospital Research Foundation. induced with pancuronium bromide $(0.5 \mathrm{mg} / \mathrm{kg})$. The piglet was subsequently ventilated with a Bourne LS104 infant ventilator. The sagittal sinus was exposed via a burr hole in the anterior skull, and a catheter was introduced through a 22 gauge needle puncture.

Experimental protocol. All animals were maintained with normal arterial blood gas values for $120 \mathrm{~min}$ following the completion of surgery. Body temperature was continuously monitored and maintained at $39 \pm 1^{\circ} \mathrm{C}$ throughout the study with an electric heating pad. The nitrous oxide gas mixture was replaced with compressed air and $25 \%$ oxygen at the beginning of this period. The study consisted of four blood flow determinations. During each, cardiac output, brain blood flow, arterial and sagittal sinus $\mathrm{O}_{2}$ contents, arterial blood gas tensions, and hematocrits were obtained. A baseline (time 0) measurement was made under normoxic and normocarbic conditions. Respiratory alkalosis $\left(\mathrm{PaCO}_{2}<20 \mathrm{~mm} \mathrm{Hg}\right)$ was induced by increasing the tidal volume by $30 \%$ and the respiratory rate by $50 \%$ in eight piglets. Three additional measurements were made 30,60 , and 120 min following the initiation of hyperventilation. A constant degree of respiratory alkalosis was maintained throughout the study. Blood volume was maintained by replacing the blood withdrawn with age-matched piglet blood. Following the 120min blood flow determination, the piglet was sacrificed with pentobarbital and the brain removed and preserved in $10 \%$ formalin for 5-7 days. The brain was then divided into the following right and left sections; cerebrum, thalamus, cerebellum, and brain stem.

Four piglets served as normocarbic controls to assess the stability of this animal preparation. They were treated in a similar manner to the study piglets but were not hyperventilated.

Methodology. Blood flow and cardiac output were measured with microspheres $(15 \pm 2 \mu \mathrm{m}$ diameter) with the following nuclides: $113 \mathrm{Sn}, 46 \mathrm{Sc}, 57 \mathrm{Co}$, and $103 \mathrm{Ru}$ (New England Nuclear, Boston, MA). The radioactivity per unit weight of the miocrosphere solution was determined just prior to the microsphere injection. Approximately $9 \times 10^{5}$ microspheres were injected into the left ventricle and the catheter was flushed with 5 $\mathrm{ml}$ of heparinized saline over $15-20 \mathrm{~s}$ immediately following the microsphere injection. The reference organ withdrawal sample from the ascending aorta was collected for 2 min beginning $10 \mathrm{~s}$ prior to the microsphere injection, at a constant withdrawal rate of $1.03 \mathrm{ml} / \mathrm{min}$. No change in mean arterial pressure was observed during the microsphere injection and the criteria necessary to ensure measurement accuracy to within $5 \%$ were met during the study (6). A small sample of lung tissue was removed at the end of the study to monitor for shunting of blood through the ductus arterosis (from the aorta to pulmonary artery). We predetermined that a blood flow measurement would be discarded if there was a change of $20 \%$ or greater (compared to baseline normocarbic value) in the percentage cardiac output delivered to the lung, however, this did not occur during any of the hypocarbic determinations. 
Blood, tissue, and microsphere solution radioactivity were measured using a Packard gamma spectrometer and blood flow data generated with software written for an IBM PC. The program corrected for isotope spillover and decay. Blood flow was calculated by determining the ratio of $\mathrm{cpm}$ in the brain and reference blood sample and the rate of withdrawal of the reference blood sample (7). Similarily, cardiac output was calculated from the following equation:

$$
\begin{aligned}
\text { cardiac output }= & \frac{\mathrm{cpm} \text { injected }}{\text { cpm reference sample }} \\
& \times \text { rate of withdrawal of reference sample }
\end{aligned}
$$

The radioactivity of the microsphere solution injected was determined by obtaining (in triplicate) small aliquots of the microsphere solution $(0.02 \pm 0.005 \mathrm{~g})$ just prior to injection and by determining the exact weight of microsphere solution injected. Residual amounts of microsphere solution remaining in the injection syringe and stopcock were measured by flushing the syringe and stopcock into counting vials with $10-20 \mathrm{ml}$ of normal saline. Blood flow to the brain was expressed as $\mathrm{ml} / \mathrm{min} / 100 \mathrm{~g}$ wet (nonfixated) weight, and cardiac output as $\mathrm{ml} / \mathrm{min} / \mathrm{kg}$ body weight.

$\mathrm{O}_{2}$ contents of the arterial and sagittal sinus blood samples were measured with a Lex- $\mathrm{O}_{2}-\mathrm{Con} \mathrm{O}_{2}$ analyzer and arterial blood gas tensions measured using standard electrodes (Instrumentation Labs, Waltham, MA). Hematocrit was measured by the microhematocrit method.

Data analysis. Cerebral oxygen delivery and consumption were calculated using the Fick equation. $\mathrm{O}_{2}$ delivery = cerebral blood flow $\times$ arterial $\mathrm{O}_{2}$ content $\left(\mathrm{CaO}_{2}\right) ; \mathrm{O}_{2}$ consumption $=$ cerebral blood flow $\times$ [arterial $\mathrm{O}_{2}$ content - sagittal sinus $\mathrm{O}_{2}$ content $\left(\mathrm{CvO}_{2}\right)$ ]. Cerebral extraction fraction was determined by: $\mathrm{CaO}_{2}-\mathrm{CvO}_{2} / \mathrm{CaO}_{2} \times 100$.

Analysis of variance for repeated measurements was used to detect statistical significance. If a significant difference was found, the Dunnet's multiple range $t$ test was used to compare the means. A two-way analysis of variance was used to interpret the interaction between regional changes in brain blood flow and time. Control animals were not compared directly with study animals but were used to assess stability of brain blood flow and oxygen consumption over time. All data are expressed as mean $\pm \mathrm{SD}$.

\section{RESULTS}

Table 1 summarizes the heart rate, mean arterial blood pressure, and arterial blood gas values during the study. There were no changes in heart rate, mean arterial blood pressure, and $\mathrm{PaO}_{2}$ As expected, hyperventilation resulted in increases in arterial $\mathrm{pH}$ as a result of hypocarbia. It should be noted that a constant level of respiratory alkalosis was maintained throughout the 120-min study period. The hematocrit values remained stable throughout the study $(30 \pm 5 \%)$.

Figure 1 and 2 depict hypocarbic induced changes in total brain blood flow and cardiac output. Brain blood flow decreased $(40 \%)$ at $30 \mathrm{~min}$ following the induction of respiratory alkalosis and remained decreased during the entire study. However, there was a gradual increase in brain blood flow over time, so that by $120 \mathrm{~min}$, there was greater brain blood flow than at the $30-\mathrm{min}$

Table 1. Heart rate (HR), mean arterial pressure (MAP), and arterial blood gas values during the study (mean $\pm S D)(n=8)$

\begin{tabular}{lcccc}
\hline \multicolumn{1}{c}{ Time } & $\mathrm{B}$ & 30 & 60 & 120 \\
\hline $\mathrm{HR}(\mathrm{bmp})$ & $225 \pm 33$ & $246 \pm 40$ & $237 \pm 39$ & $234 \pm 41$ \\
$\mathrm{MAP}(\mathrm{mm} \mathrm{Hg})$ & $85 \pm 14$ & $79 \pm 16$ & $83 \pm 17$ & $81 \pm 15$ \\
$\mathrm{pH}$ & $7.42 \pm 0.04$ & $7.65 \pm 0.07$ & $7.67 \pm 0.07$ & $7.66 \pm 0.08$ \\
$\mathrm{pCO}(\mathrm{mm} \mathrm{Hg})$ & $38 \pm 2$ & $16 \pm 3$ & $17 \pm 3$ & $16 \pm 3$ \\
$\mathrm{pO}_{2}(\mathrm{~mm} \mathrm{Hg})$ & $107 \pm 31$ & $109 \pm 30$ & $105 \pm 28$ & $105 \pm 29$ \\
\hline
\end{tabular}

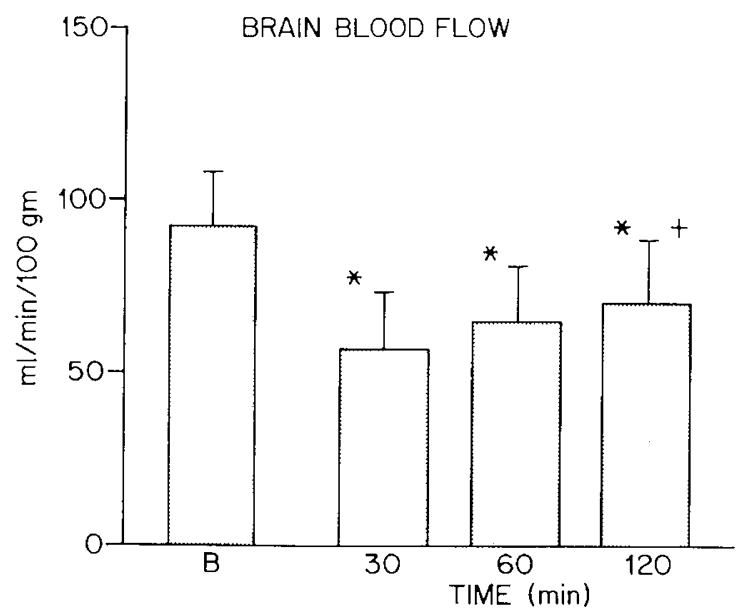

Fig. 1. Total brain blood flow during normocarbia baseline $(B)$ and following hyperventilation (mean $\pm \mathrm{SD}$ ). The asterisk designates a significant difference $(p<0.05)$ from baseline measurement. The daggar designates a significant difference from 30-min hypocarbic measurement $(n=8)$.

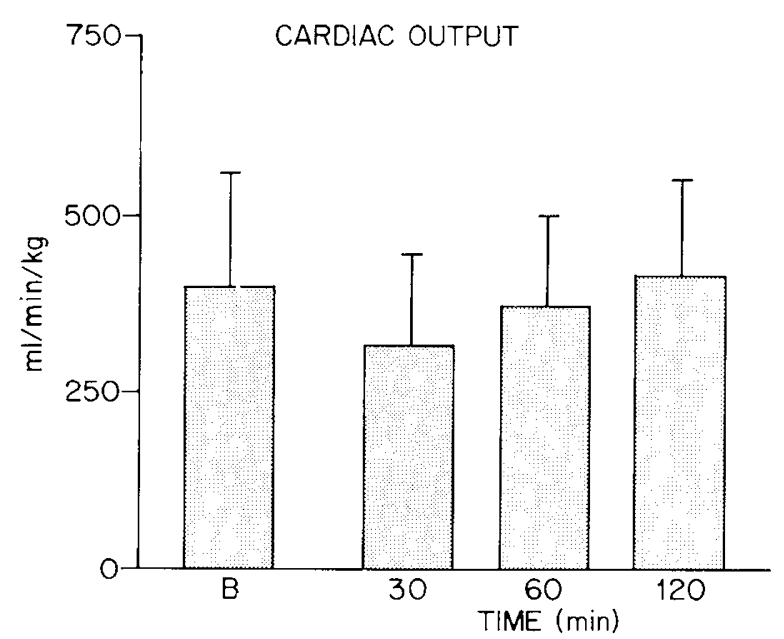

Fig. 2. Cardiac output during normocarbic baseline $(B)$ and following onset of hyperventilation (mean $\pm \mathrm{SD})(n=8)$.

determination. Cardiac output did not vary significantly, although there was a trend toward decreased cardiac output with the induction of hyperventilation. The percent cardiac output reaching the brain decreased from $5.8 \pm 1.5 \%$ during normocarbia to $4.3 \pm 0.9 \%, 4.0 \pm 0.8 \%, 4.4 \pm 1.7 \%$ at 30,60 , and 120 min. Only the 60 min was statistically lower than the normocarbic baseline.

Figure 3 depicts the regional changes in brain blood flow during hypocarbia. To correct for regional flow differences observed during the baseline determination, the flows are expressed as percentage change from baseline flow to that region. The percentage decrease in flow to the cerebrum was greater than that observed in the other regions at the 30- and 60-min determinations.

Figure 4 summarizes the changes in cerebral oxygen delivery, oxygen extraction, and oxygen consumption. Hypocarbic-induced vasoconstriction decreased cerebral oxygen delivery during all three hypocarbic determinations. However, by $120 \mathrm{~min}$ oxygen delivery had significantly increased from the 30 -min value. Cerebral oxygen extraction rose and was maintained at a consistent level during all three hypocarbic determinations. Cerebral oxygen consumption was decreased at only the 30-min determination.

Table 2 summarizes thie data from the four control animals maintained with normocarbia throughout the entire study. There 


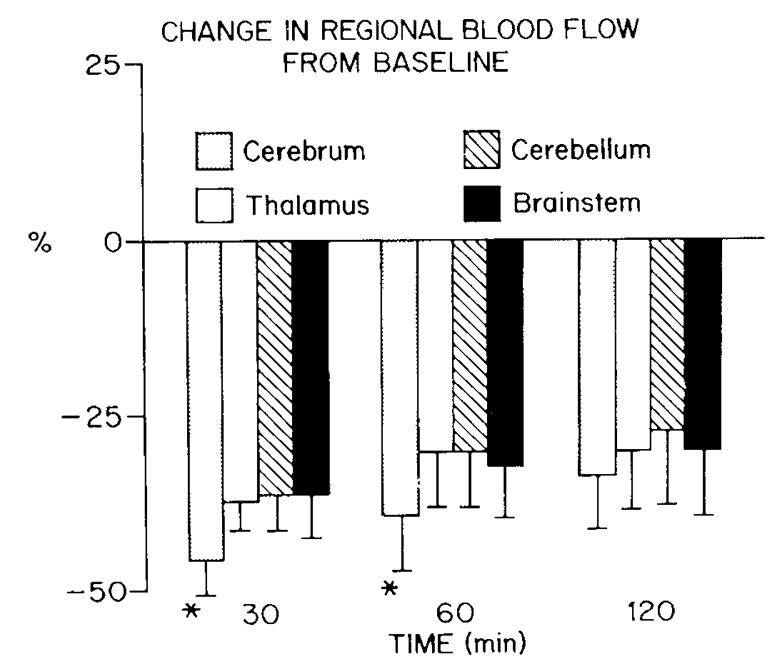

Fig. 3. Regional biood flow during hyperventilation expressed as percentage change in blood flow to that region during normocarbia. Asterisk denotes a significant difference $(p<0.05)$ between regions $($ mean $\pm \mathrm{SD})(n=8)$.

were no significant changes in arterial blood gases, heart rate, mean arterial pressure, cardiac output, or brain blood flow. Similarly, cerebral oxygen consumption extraction ratio remained constant.

\section{DISCUSSION}

In this study, hypocarbic alkalosis was achieved by increasing both the tidal volume and respiratory rate in paralyzed piglets. Positive pressure hyperventilation has the potential to impede venous return to the heart and consequently decrease cardiac output. There was a trend toward increased heart rate and decreased arterial blood pressure during hyperventilation but no significant alterations in cardiac output were observed. Hyperventilation did result in cerebral vasoconstriction as demonstrated by the changes in percentage cardiac output going to the brain. Only the 60 -min determination was significantly lower than baseline due to large variations in cardiac output. Intracranial pressure and/or cerebral venous pressure were not monitored during this study. Intracranial pressure would be expected to decrease with hyperventilation due to the reduction in cerebral arterial blood flow. However, positive pressure ventilation has the potential of impeding cerebral venous return and this would have an opposite effect on intracranial pressure. Further studies of the effects of hyperventilation on intracranial pressure and cerebral venous pressure are needed to clarify this question.

The four control animals were studied to assess the stability of this surgical preparation. We did not demonstrate a gradual decrease in cerebral blood flow over time, as has been observed by other investigators studying acutely instrumented artificially ventilated animals (8). This observation may have been due to differences in anesthesia, body temperature maintainence, or be secondary to a longer stabilization period following surgery in both our control and hyperventilated animals. Muscle paralysis was initiated following surgery in both groups. Although transient changes in heart rate and arterial pressure have been reported in human neonates following pancuronium administration (9), no significant alterations in cerebral blood flow or oxygen consumption have been observed in the newborn lamb (10).

The magnitude of the decrease in cerebral blood flow (40\%) at $30 \mathrm{~min}$ following the induction of hyperventilation is similar to that observed in previous studies $(1,2)$. Whether hypocarbiainduced vasoconstriction results in significant cerebral ischemia remains controversial (11). Earlier work does not support the concept of significant brain hypoxia subsequent to acute hypocarbic induced vasoconstriction (11); however, several recent
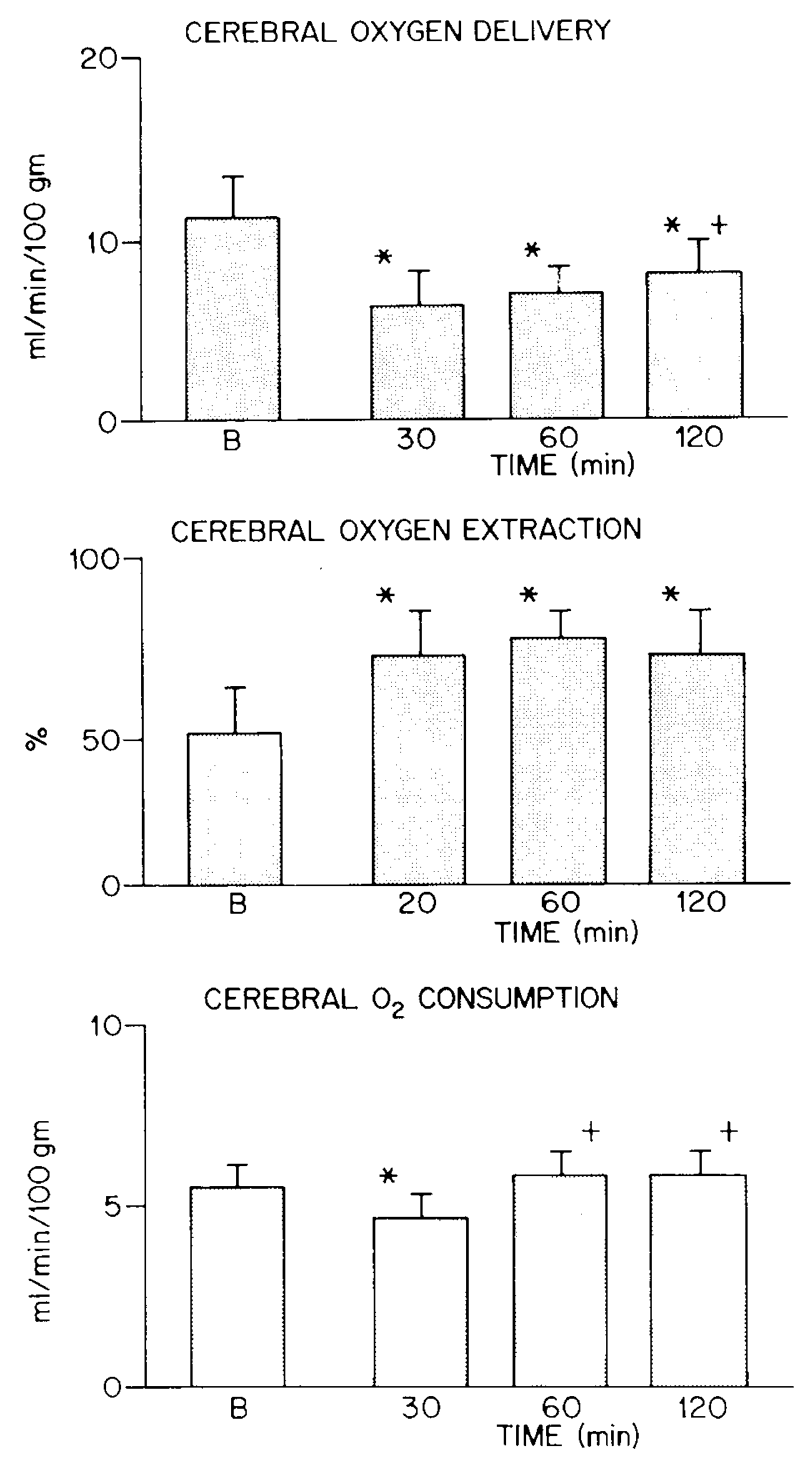

Fig. 4. Cerebral oxygen delivery, cerebral oxygen extraction, and cerebral oxygen consumption during normocarbic baseline $(B)$ and following hyperventilation. The asterisk designates a significant difference $(p<0.05)$ from baseline measurement. The daggar designates a significant difference from the 30 -min measurement (mean $\pm \mathrm{SD})(n==$ $8)$.

Table 2. Blood gas, cardiac output (CO), brain blood flow $(B B F)$, cerebral oxygen consumption $\left(\mathrm{VO}_{2}\right)$, and extraction $\left(\mathrm{EO}_{2}\right)$ values in control $(n=4)$ animals maintained with normocarbia throughout the study (mean 上 SD)

\begin{tabular}{lcccc}
\hline \multicolumn{1}{c}{ Time } & $\mathrm{B}$ & 30 & 60 & 120 \\
\hline $\mathrm{pH}$ & $7.39 \pm 0.03$ & $7.39 \pm 0.03$ & $7.38 \pm 0.03$ & $7.37 \pm 0.04$ \\
$\mathrm{pCO}_{2}(\mathrm{~mm} \mathrm{Hg})$ & $41 \pm 3$ & $39 \pm 2$ & $41 \pm 3$ & $40 \pm 3$ \\
$\mathrm{pO}_{2}(\mathrm{~mm} \mathrm{Hg})$ & $102 \pm 19$ & $103 \pm 24$ & $100 \pm 19$ & $105 \pm 21$ \\
$\mathrm{CO}(\mathrm{ml} / \mathrm{mm} / \mathrm{kg})$ & $481 \pm 176$ & $401 \pm 179$ & $475 \pm 208$ & $467 \pm 149$ \\
$\mathrm{BBF}(\mathrm{ml} / \mathrm{min} /$ & $94 \pm 5$ & $97 \pm 9$ & $96 \pm 11$ & $98 \pm 6$ \\
$\quad 100 \mathrm{~g})$ & & & & \\
$\mathrm{VO}_{2}(\mathrm{ml} / \mathrm{min} /$ & $5.7 \pm 0.7$ & $5.9 \pm 0.6$ & $5.6 \pm 0.8$ & $5.7 \pm 0.7$ \\
$\quad 100 \mathrm{~g})$ & $52 \pm 4$ & $54 \pm 2$ & $52 \pm 2$ & $52 \pm 4$ \\
$\mathrm{EO}_{2}(\%)$ & & & &
\end{tabular}

studies have demonstrated hyperventilation induced cerebral hypoxia $(12,13)$. Our data demonstrate an acute but transient decrease in cerebral oxygen consumption in response to hypocarbic induced cerebral vasoconstriction. The physiologic signif- 
icance of this $15 \%$ decrease in oxygen consumption cannot be determined from this study.

The striking finding in this study is the gradual increase in cerebral blood flow over the 2 -h period of hyperventilation. This increase in cerebral blood flow serves to restore cerebral oxygen consumption, following the acute decrease in cerebral blood flow noted with the onset of hyperventilation. The finding of gradually increasing cerebral blood flow during prolonged hypocarbia differs significantly from previous observations in newborn lambs and puppies $(1,14)$. This discrepancy may be species specific, but could also be related to experimental methodology as several studies have shown that cerebral blood flow gradually decreases during prolonged anesthesia $(8,15)$.

The mechanism responsible for the gradual increase in cerebral blood flow during prolonged hypocarbia cannot be clearly elucidated from our data. One likely explanation may be the coupling of cerebral metabolism to blood flow (16). Decreases in oxygen and other substrate availability may induce locally medicated changes in vascular resistance overriding the influence of hypocarbia on the cerebral circulation. Thus, the initial effect of hypocarbia was to induce a state of ischemic hypoxia; this, in turn, may have resulted in the local release of vasoactive substances which counteracted the hypocarbic induced cerebral vasoconstriction. This vascular escape phenomenon associated with prolonged severe hypocarbia may be the explanation of the discrepancy between the observation in animal studies of significant hypocarbia induced reductions in cerebral blood flow and the lack of long-term evidence of ischemic sequelae in human neonates treated with prolonged hyperventilation for several days.

Oxygen consumption depends on both oxygen delivery and oxygen extraction (17). Under most circumstances, cerebral oxygen consumption is maintained by alterations in oxygen delivery, and thus, cerebral blood flow rather than alterations in oxygen extraction $(17,18)$. Hypocarbia is the one notable exception during which extraction increases dramatically (17). As the fetus and newborn of many species have erythrocytes with increased oxygen affinity $(19,20)$, theoretically they would be expected to have a limited ability, when compared to mature animals, to increase oxygen extraction in the face of severe hypocarbicinduced vasoconstriction. In the present study, cerebral oxygen extraction increased during hypocarbia, however, the increase was not adequate to compensate for the decrease in oxygen delivery occurring at this time, and oxygen consumption therefore decreased. It appears that the piglet cerebrum is limited in the amount of oxygen it can extract. Data from this study suggest this level to be near $75 \%$.

In summary, gradual increases in cerebral blood flow during prolonged hypocarbia restored oxygen delivery and subsequently restored cerebral oxygen consumption. The regional differences in cerebral blood flow during hypocarbia are similar to those observed in previous studies (2). Whether these differences are due to regional differences in metabolic rate remain to be determined.

\section{REFERENCES}

1. Cartwright D, Gregory GA, Lou H, Heyman MA 1984 The effcts of hypocarbia on the cardiovascular system of puppies. Pediatr Res 18:685-690

2. Hansen NB, Brubakk AM, Bratlid D, Oh W, Stonestreet BS 1984 The effects of variations in $\mathrm{PaCO}_{2}$ on brain blood flow and cardiac output in the newborn piglet. Pediatr Res 18:1132-1136

3. Ferrara B, Johnson DE, Chang PN, Thompson TR 1984 Efficacy and neurologic outcome of profound hypocapneic alkalosis for the treatment of persistent pulmonary hyperension in infancy. $J$ Pediatr 105:457-46

4. Bernbaum J, Russell P, Sheridan P, Gewitz M, Fox W, Peckham G 1984 Longterm follow-up of newborns with persistent pulmonary hypertension. Crit Care Med 12.579-583

5. Skinhoj E 1968 CSF adaptation in man to chronic hypo- and hyper- capnia and its relation to CSF pH. Scand J Lab and Clin Invest 102(supp):A8-10

6. Dole WP, Jackson DL, Roseblatt JI, Thompson WL 1982 Relative error and variability in blood flow measurements with radiolabelled microspheres. Am J Physiol 243:H371-378

7. Heymann MA, Payne BD, Hoffman J, Rudolph AM 1977 Blood flow measurements with radionuclide-labelled particles. Prog Cardiovasc Dis 20:55

8. Raichle ME, Posner JB, Plum F 1970 Cerebral blood flow during and after hyperventilation. Arch Neurol 23:394-402

9. Cabal LA, Siassi B, Artal R Gonzalez F, Hodgman J, Plajstek C 1985 Cardiovascular and catecholamine changes after administration of pancuronium in distressed neonates. Pediatrics 75:284-287

10. Belik J, Wagerle LC, Delivoria-Papadopoulos M 1984 Cerebral blood flow and metabolism following pancuronium bromide in newborn lambs. Pediatr Res 18:1305-1308

11. Bruce DA 1984 Effects of hyperventilation on cerebral blood flow and metabolism. Clin Perinatol 11:673-681

12. Kennealy JA, McLennan JE, Loudon RG, McLaurin RL 1980 Hyperventilation induced cerebral hypoxia. Am Rev Respir Dis 122:407-412

13. Grote J, Zimmer K, Schubert R 1981 Effects of severe arterial hypocapnia on regional blood flow regulation, tissue pO2 and metabolism in the brain cortex of cats. Pflugers Arch 391:195-199

14. Gregory GA, Ong W, Tweed A, Wade JG 1982 The effects of alkalosis and hypoxemia on cerebral metabolism in the newborn lamb. Anesthesiology 57A:424

15. Palmer NI, Thomas DJ, MacGillivray BB, DuBoulay GH, Marshall J, Russe RW, Symon L 1977 Variations in mean cerebral blood flow under anesthesia at rest and during cortical activation. Stroke 8:269-271

16. Berne RM, Winn HR, Rubio R 1981 The local regulation of cerebral blood flow. Prog Cardiovasc Dis 24:243-248

17. Jones MD Jr, Traystman RJ 1984 Cerebral oxygenation of the fetus, newborn and adult. Sem Perinatol 8:205--216

18. Jones MD Jr, Rosenberg AA, Simmons MA, Molteni RA, Koehler RC, Traystman RJ 1982 Oxygen delivery to the brain before and after birth. Science 216:324-325

19. Sacks LM, Delivoria-Papadopoulos M 1984 Hemoglobin-oxygen interactions. Semin Pernatol 8:168-183

20. Delivoria-Papadopoulos M, Martens RJ, Forster RE II, Oski FA 1974 Postnatal changes in oxygen-hemoglobin affinity and erythrocyte 2, 3 diphosphoglycerate in piglets. Pediatr Res 8:645-666 